University of Massachusetts Amherst

ScholarWorks@UMass Amherst

Communication Department Faculty Publication

Series

Communication

2020

\title{
Past Place, Present Prejudice: The Impact of Adolescent Racial Context on White Racial Attitudes
}

Seth K. Goldman

University of Massachusetts Amherst

Daniel J. Hopkins

University of Pennsylvania

Follow this and additional works at: https://scholarworks.umass.edu/communication_faculty_pubs

\section{Recommended Citation}

Goldman, Seth K. and Hopkins, Daniel J., "Past Place, Present Prejudice: The Impact of Adolescent Racial Context on White Racial Attitudes" (2020). The Journal of Politics. 127.

https://doi.org/10.1086/706461

This Article is brought to you for free and open access by the Communication at ScholarWorks@UMass Amherst. It has been accepted for inclusion in Communication Department Faculty Publication Series by an authorized administrator of ScholarWorks@UMass Amherst. For more information, please contact scholarworks@library.umass.edu. 


\title{
Past Place, Present Prejudice: The Impact of Adolescent Racial Context on White Racial Attitudes
}

\author{
Seth K. Goldman, University of Massachusetts, Amherst \\ Daniel J. Hopkins, University of Pennsylvania
}

\begin{abstract}
Extensive research on racial contexts suggests that white Americans living near black Americans adopt more negative racial attitudes. Theoretically, local intergroup exposure has been conceptualized as acting contemporaneously through various mechanisms. However, a separate body of research on political socialization indicates that adolescent experiences are often especially influential. We hypothesize that whites' racial contexts during adolescence produce prejudiced responses. We then test this hypothesis using two complementary data sets, a population-based panel conducted 2007-13 and the Youth-Parent Socialization Panel Survey (1965-97). Our analyses demonstrate the enduring influence of adolescent contexts at larger levels of aggregation: while the racial composition of whites' current counties is not a consistent predictor of racial prejudice, the racial composition of their county during high school is. Proximity during one's formative years increases racial prejudice years later, providing new insights about local contextual effects and the roots of racial prejudice.
\end{abstract}

$\mathrm{P}$ olitical divisions between blacks and whites have long been a defining feature of American politics (Kinder and Dale-Riddle 2010). Yet geographically, America is both large and varied, with some places being home to large black communities while others are overwhelmingly white. Decades ago, that geographic diversity gave rise to the "racial threat" hypothesis (Key 1949). Its core claim: whites living near large black communities feel a heightened sense that their political and social status is threatened and so adopt more hostile racial attitudes.

In the intervening decades, claims about the influence of racial contexts, the mechanisms underpinning that influence, and the conditions that facilitate it have received sustained attention (e.g., Dancygier 2010; Enos 2017; Newman 2012; Oliver 2001; Putnam 2007). Yet despite numerous studies, there is no empirical consensus on racial contexts' impacts. Scholars continue to disagree about the actual prevalence of such contex- tual effects (Acharya, Blackwell, and Sen 2018b; Oliver and Mendelberg 2000), to say nothing of their geographic scale (Dinesen and Sonderskov 2015; Hersh and Nall 2016; Oliver and Wong 2003; Wong et al. 2012). Prior research has also posited multiple mechanisms that might underpin the effects of racial contexts. It is plausible, as Key (1949) suggested, that such contextual effects are driven by perceived threats to whites' social and political status. But other mechanisms may operate as well, including economic competition, negative interpersonal encounters, and local differences in the attitudinal or information environment. ${ }^{1}$

We offer a new explanation for the indeterminacy of past findings. To date, virtually all studies on these questions have considered the effects of people's contemporary racial contexts (but see Glaser and Gilens 1997; Welch et al. 2001). The emphasis on contemporary contexts makes sense if the mechanism at work is threat due to competition for scarce resources

Seth K. Goldman (skgoldman@comm.umass.edu) is an associate professor at the University of Massachusetts Amherst, Amherst, MA 01003. Daniel J. Hopkins (danhop@sas.upenn.edu) is a professor of political science at the University of Pennsylvania, Perelman Center for Political Science and Economics, 133 S. 36th Street, Philadelphia, PA 19104.

Data and supporting materials necessary to reproduce the numerical results in the article are available in the JOP Dataverse (https://dataverse.harvard.edu /dataverse/jop). An online appendix with supplementary material is available at https://doi.org/10.1086/706461. Both data sets include restricted geographic fields that preclude their posting. Information about accessing the Youth-Parent Socialization Panel Survey is available at https://www.icpsr.umich.edu/icpsrweb /ICPSR/studies/4037, while information about accessing the National Annenberg Election Study is at https://www. annenbergpublicpolicycenter.org/data-access/. This research was reviewed and approved by the University of Pennsylvania's Institutional Review Board (822945 and 824036 ). Financial support was provided by the Annenberg Public Policy Center, the Institute for the Study of Citizens and Politics, the University of Pennsylvania School of Arts and Sciences and University Research Foundation, and the Russell Sage Foundation (awards 94-17-01 and 94-18-07 to Hopkins and W. Hobbs and 87-11-01 to Goldman and D. Mutz).

1. Prior research has used "racial threat" to refer either to the overall effects of racial contexts or to the specific effects produced by perceived threats to whites' social, political, or economic status. Here, we use racial threat only in the second, more circumscribed sense.

The Journal of Politics, volume 82, number 2. Published online January 24, 2020. https://doi.org/10.1086/706461

(C) 2020 by the Southern Political Science Association. All rights reserved. 0022-3816/2020/8202-0009\$10.00 
(Dancygier 2010; Glaser 1994). But other mechanisms may operate with particular strength in adolescence, especially given research on political socialization emphasizing the durable effects of events during one's formative years (e.g., Niemi and Jennings 1991; Sears and Levy 2003). Residential mobility in the United States is substantial: according to the 1996 General Social Survey (GSS), 31\% of respondents lived in a different state than where they grew up. In light of that mobility and the particular influence of adolescent experiences, this paper hypothesizes that one's local intergroup context during those formative years can shape racial prejudice into adulthood.

We first test this hypothesis using a multiwave, nationally representative panel conducted by Growth from Knowledge (GfK). This population-based panel of Americans began in late 2007 and continued through the 2008, 2010, and 2012 elections. Importantly, it includes measures of respondents' place of residence in high school and during the survey. As a consequence, we are able to assess the impact of adolescent and contemporaneous racial contexts on white racial attitudes among the same respondents at multiple points in time. Given its sample size ( $n=7,559$ from 1,682 respondents) and coverage of the US population, this data set provides a powerful test of our hypothesis.

Our varied empirical analyses bolster the hypothesis about the impact of adolescent intergroup exposure. Pooling the six survey waves for which prejudice was measured, we observe a consistent, positive correlation between the size of the black population in respondents' high school counties and their selfreported levels of prejudice. According to one estimate, if a non-Hispanic white person grew up in a county with no African Americans, we should expect that person's prejudice to be 2.3 points lower ${ }^{2}$ than an otherwise similar respondent growing up in a county that is $18 \%$ black, which is one standard deviation above the mean. This effect is $15 \%$ of the prejudice measure's standard deviation. The effect does not differ notably across several contextual or individual-level factors, such as whether the respondents were over 50, grew up in counties with higher unemployment or education, or were located in the South.

Since Key (1949), racial contexts have been measured primarily at the county level (e.g., Glaser 1994; Wright 1977). But counties are heterogeneous units that are coarse measures of social environments, and our 2007-13 panel has few alternative measures of respondents' adolescent contexts. To test the robustness of our results and to probe select mechanisms that might underpin them, we next turn to the Youth-Parent Socialization Panel Survey (YPSPS), which followed a cohort of 1965 high school seniors for 32 years. Respondents to the

2. The associated standard error is 0.7 points.
YPSPS were initially interviewed in 1965, as were their classmates and parents. They were reinterviewed in 1973, 1982, and 1997, providing us with varied measures of respondents' social and demographic contexts.

While the vast majority of prior research on racial contexts has employed a single data set (but see Acharya et al. 2018b), the two data sets analyzed here have complementary strengths that lend particular credibility to any results that emerge in both. The advantages of the 2007-13 panel include its larger sample size and respondents from varying generations. For its part, the YPSPS provides the ability to track the racial attitudes of a cohort that came of age during the Civil Rights era from their late teens into their forties and fifties. Critically, the YPSPS provides more nuanced measures of intergroup contexts, such as parents' and classmates' racial attitudes, as well as the percentage of high school classmates who were black.

In the post-high school YPSPS waves, contemporary measures of white respondents' racial contexts prove to be weak predictors of prejudice. But the racial demographics of the respondents' county while in high school predict their levels of prejudice years later. Strikingly, this relationship remains even accounting for a variety of other potential influences during adolescence, such as the racial attitudes of respondents' parents and classmates. In fact, by 1982, respondents' adolescent racial contexts are stronger predictors of their levels of prejudice than are their parents' racial attitudes. What is more, it is larger spatial units such as counties or even clusters of counties that seem to produce prejudiced responses - attending a high school with more black students had either a null effect or reduced prejudice. Although we lack the statistical precision to know whether this effect fades between 1982 and 1997, the evidence is consistent with a declining effect in the final wave.

Considered jointly, the results from two independent analyses provide an explanation for the prior inconsistent findings. If the most influential local context is the adolescent context, surveys that measure contemporary contexts alone will have significant measurement error. While future research should continue to probe the mechanisms underpinning the effects of racial contexts, the shift to emphasizing adolescent racial contexts also foregrounds some mechanisms over others. For instance, these results undercut the role of threat due to contemporary, instrumental concerns such as competition for jobs or power. Nor does regular face-to-face contact seem to explain these results, as the influence of adolescent racial contexts operates over larger geographic units than high schools. In fact, most group members in these places likely experience proximity without sustained contact, leading to increased hostility (Enos 2017; Pettigrew and Tropp 2011). Instead, the indication is that racial contextual influence stems from experiences 
prior to adulthood and is not grounded in competition for scarce resources. Prejudice evident in 2012 can have roots in experiences decades earlier, suggesting its durability.

\section{PRIOR RESEARCH AND HYPOTHESES}

In his landmark 1949 study of the South, V. O. Key identified a correlation between counties' black populations and the political engagement and attitudes of local whites. In his words, "the presence of large numbers of Negroes is associated with intense political consciousness" (Key 1949, 517). Yet 71 years after Key's work, questions remain. This section first reviews prior research on racial contexts and whites' attitudes, almost all of which has focused on contemporary contexts. One goal in doing so is to identify the mechanisms commonly thought to underpin racial contextual influence, including competition for scarce resources, negative interpersonal encounters, and differing information or attitudinal environments. This section then integrates prior research with a separate body of work on political socialization to develop the hypothesis that whites' adolescent racial contexts are likely to influence levels of prejudice. While some of the mechanisms advanced to explain the impact of contemporary contexts can be extended straightforwardly to make sense of adolescent contexts, others cannot. The possibility that adolescent contexts may generate prejudice also raises the prospect of novel mechanisms.

\section{THE INFLUENCE OF RACIAL CONTEXTS AND ITS UNDERPINNINGS}

Existing research has often considered the mechanisms by which racial context influences individuals, and the related questions of the geographic scale at which it operates and attitudes and behaviors liable to change as a result (Dinesen and Sonderskov 2015; Hersh and Nall 2016; Newman 2012; Oliver and Wong 2003; Wong et al. 2012). For instance, some scholars explain the effects of racial contexts as a product of competition for scarce resources, whether those resources are economic or political (Dancygier 2010; Glaser 1994; Glaser and Ryan 2013). In either case, we might expect such threats to operate in the spatial unit in which those resources are contested, whether it is a labor market or a political jurisdiction (Oliver and Wong 2003).

Other strands of research emphasize different mechanisms through which shared space could heighten whites' prejudice. One is via casual interpersonal encounters that are interpreted negatively. Enos (2017) demonstrates that simply sharing a train platform with Spanish speakers can induce anti-immigration attitudes. In a similar vein, white voter turnout in Chicago declined after the removal of nearby housing projects whose residents were largely black. In these cases, diverse contexts produce prejudice through close interpersonal proximity that nonetheless lacks meaningful interaction, a mechanism that operates in small social environments. Yet even absent actual interpersonal exposure, the mere knowledge of other social groups nearby might make race-related issues salient. Another prospect emphasizes local information environments, either because of the norms they promote (Acharya et al. 2018b; Oliver and Mendelberg 2000) or the content of local conversations, social attitudes, and media coverage (Hopkins 2012). In this view, larger black populations in the surrounding area may shape local news coverage or the content of local politics. In such cases, the relevant geographic units are potentially larger, perhaps including media markets or metropolitan areas.

\section{EARLY-LIFE RACIAL CONTEXT AND PREJUDICE}

Whites' contemporary racial contexts may not be the onlyor even the most influential - contextual factor at work. Here, we develop the alternative hypothesis that adolescent racial contexts are likely to generate prejudice. Once formed, prejudiced attitudes are thought to be highly stable and resistant to new information. Over-time studies of public opinion suggest that white racial attitudes change only over years or decades, if they change at all (Schuman et al. 1997). One explanation for this stability is the tendency to dismiss positive counter-stereotypical out-group members as unrepresentative (Rothbart and John 1985). This self-perpetuating characteristic of prejudice makes it important to understand its early formation.

Research on political socialization provides an added impetus to understand whites' initial adoption of racial attitudes. Social scientists have long known that people are especially susceptible to influence in adolescence and early adulthood (e.g., Niemi and Jennings 1991). ${ }^{3}$ In fact, the effects of political events experienced during those critical years are evident decades later (Sears and Valentino 1997), as generational cohorts continue to show the distinctive effects of the period when they matured. Such persistence has been identified in racial attitudes as well (Schuman et al. 1997), a fact that might explain how contemporary racial attitudes are related to the presence of slavery in US counties 150 years ago (Acharya et al. 2018b), or why pre-adult racial attitudes shape political ideology into adulthood (Sears and Funk 1999). Still, there are a variety of early-life social and demographic contexts that might shape prejudice, from the attitudes of one's friends or parents to the demographic composition of one's high school or larger community. ${ }^{4}$

3. "Adolescence" is formally defined as the transitional period between childhood and adulthood, roughly between 13 and 21 years of age.

4. Intriguingly, results from the YPSPS indicate that the parent-child correlation in attitudes on racial issues is actually lower than that on other salient political issues, although it remains sizable (Jennings et al. 2009). 
Racial attitudes depend strongly on social networks or other peer effects during the formative high school years, even more so than other political attitudes (Jennings, Stoker, and Bowers 2009, 792). Thus, by focusing exclusively on contemporary racial contexts, existing research may have missed the impact of racial contexts during precisely the years when they are most influential. That possibility is given added weight by Wright's (1977) finding that support for segregationist candidate George Wallace in 1968 was better predicted by the 1940 racial context than the 1970 racial context (see also Miller and Sears 1986; Stolle and Harell 2013).

To be sure, whites' racial attitudes evolve even after the critical years of adolescence (e.g., Glaser and Gilens 1997; Goldman and Mutz 2014). But by combining prior research on political socialization with studies of racial contexts, we reach a clear hypothesis: the racial context during one's adolescence should have a particular influence on her racial attitudes, even decades later. Through their near-exclusive focus on contemporaneous contexts, prior studies of racial contexts might have undersold their influence. That emphasis on contemporary contexts also means that prior studies have been better positioned to test variants of racial contextual influence that stem from perceived threats to scarce resources than variants stemming from intergroup exposure or local attitudinal climates.

\section{THE MECHANISMS OF RACIAL CONTEXTUAL INFLUENCE IN ADOLESCENCE}

The question of which adolescent racial contexts are likely to prove influential is related to the question of how adolescent racial contexts might influence prejudice. We saw above that intergroup exposure is one mechanism through which immediate social contexts such as high schools or neighborhoods might shape attitudes and that mechanism could operate in adolescence as well. White and black students commonly selfsegregate, limiting opportunities for interracial friendship (Moody 2001). Children then form their own theories for this separation and often "infer that the social divisions they observe must have been caused by meaningful, inherent differences between groups" (Bigler and Liben 2007, 164). Overall, racially diverse schools sometimes heighten racial prejudice (Gerard 1988; Moody 2001). But schools are not the only site that might have a lasting impact on adolescents' racial attitudes. Another possibility is that brief, casual encounters elsewhere might prove influential. Consistent with the studies of adults discussed above (e.g., Enos 2017), scholarship with children shows that when social contexts increase the salience of group categories, negative intergroup attitudes often result (Bigler and Liben 2007). Proximate exposure that does not entail sustained contact or meaningful interaction may exacerbate prejudice.
More diverse contexts might also influence the attitudes that white parents transmit to their children, either by shaping parental attitudes or their salience in family conversations (Blinder 2007). Histories of the US South detail the centrality of racial divisions and segregation in children's socialization (DuRocher 2011; Ritterhouse 2006). Diverse contexts have the potential to influence the attitudinal climate among one's classmates, friends, and neighbors as well, and so to operate through community socialization. Alternatively, diverse local contexts might shape the tenor of local political appeals or information through local media coverage as well as social networks (Hopkins 2012).

To the extent that racial contexts' influence is driven by conflict over scarce resources, contemporary contexts are likely to be the site of that conflict. For that reason, theories emphasizing perceived threats to scarce economic or political resources are at a disadvantage when explaining the impact of adolescent contexts. Economic competition would only be likely to influence prejudice among adolescents if it first shaped their parents' attitudes, or else the attitudinal climate of the community generally. Fortunately, the various pathways identified here differ in the social and geographic units and time frames within which they operate, providing empirical leverage to tease them apart.

\section{STUDY 1: THE 2007-13 PANEL SURVEY}

To assess the impact of racial contexts on white racial attitudes, we turn first to a unique, eight-wave, nationally representative panel survey spanning fall 2007 through winter 2013. The first five waves, which cover fall 2007 through winter 2009, were part of the 2008 National Annenberg Election Study (NAES). The 2008 NAES panel survey began with more than 20,000 respondents, who were then asked to complete each subsequent wave; in addition, fresh samples of respondents were added to each wave. In fall 2010, as part of the Russell Sage Recontact Study, we reinterviewed a representative subsample of 3,263 nonHispanic white respondents from the 2008 NAES. Finally, waves 7 and 8 were fielded in fall 2012 and winter 2013 as part of the Institute for the Study of Citizens and Politics (ISCAP) panel, for which we recontacted a representative subsample of 2008 NAES respondents $(n=2,606) .^{5}$

All of the data were collected over the internet by GfK (formerly Knowledge Networks), which recruited a large, nationally representative sample of adults using address-based sampling

5. The specific dates of all eight waves of the panel survey were as follows: wave 1: October 2, 2007-January 1, 2008; wave 2: January 1-March 31, 2008; wave 3: April 2-August 29, 2008; wave 4: August 29-November 4, 2008; wave 5: November 5, 2008-January 31, 2009; wave 6: September 21, 2010October 6, 2010; wave 7: October 20-29, 2012; and wave 8: November 14, 2012-January 29, 2013. 
and random-digit dialing. Online surveys are particularly valuable when asking about socially sensitive issues such as prejudice, since they may reduce social desirability biases. GfK recruits individuals with and without internet access, and participants can be provided with a laptop and internet access. For the analyses in this study, we examine the responses of the 1,780 non-Hispanic whites who participated in the final wave. ${ }^{6}$

For theoretical and practical reasons, we use the county to measure racial contexts. Counties are large enough to capture more casual encounters even when neighborhoods are highly segregated (Oliver and Wong 2003). In most cases, they are sufficiently diverse as to permit substantial residential selection within their boundaries. And because people commonly travel outside of their census tracts and ZIP codes, using either as the level of aggregation would likely fail to capture many instances of exposure to blacks. Meanwhile, the state clearly represents a geographic area that few people traverse regularly, making it too large to capture regular intergroup exposure. As a practical matter, we seek a geographic unit that has been roughly comparable since as early as 1940. ZIP codes did not come into consistent use until decades later. Further, the county has been the most common level of aggregation in prior research on racial contexts (e.g., Acharya et al. 2018b; Glaser 1994; Hopkins 2010; Key 1949; Newman 2012; Wright 1977). One disadvantage of using counties, however, is their heterogeneity. They vary in size from Los Angeles County (population 9.8 million) to rural counties with populations under 5,000 people.

The central independent variables are drawn from US census data and summarized in table 4 (tables 4-20 are available online). The first is the share of a respondent's current county that was black in 2010 - our measure of contemporary contexts - while the second is the share of a respondent's high school county that was black. To measure our respondents' county during their formative years, we began with their openended answers to a question included on wave 7 about the place where they attended high school for the longest time. ${ }^{7}$ Of the 1,780 non-Hispanic white respondents, 1,455 listed a place in the United States for which we could identify the corre-

6. For the 2008 NAES, the cumulative response rates for the three panel waves we emphasize $(3,4$, and 5 ) are $8.6 \%, 8.6 \%$, and $8.1 \%$. These were computed using the household recruitment rate $(21.0 \%, 21.2 \%$, and $21.0 \%)$, the household profile rate $(55.1 \%, 55.5 \%$, and $55.7 \%)$, and the study completion rate $(74.3 \%, 73.1 \%$, and $69.1 \%)$. For the 2010 recontact wave, the cooperation rate was $83.7 \%$; for the 2012 pre-election wave, the cooperation rate was $72 \%$ (of whom $95 \%$ also participated in the post-election wave)

7. The question asked: "Please tell us the town/city and American state where you attended high school for the longest period of time. If you were living outside the United States at the time, please list the country where you were living instead." sponding county. We then used data from each US census between 1940 and 2010 to identify key demographics of the county that the respondent lived in during high school. ${ }^{8}$

Our dependent variable is a standard, stereotype-based measure of racial prejudice, in use on the General Social Survey and the American National Election Study (ANES) since 1990 and 1992, respectively. Starting in the latter part of wave 3 (July 17, 2008) and continuing on subsequent waves, whites were asked to rate whites and blacks on three scales ranging from hardworking to lazy, intelligent to unintelligent, and trustworthy to untrustworthy. To create a measure of the extent to which whites favor their own "in-group" over the black "outgroup," we subtracted ratings of blacks from ratings of whites for each dimension, and then averaged the results. ${ }^{9}$ Note that we recode respondents who rate blacks more highly than whites to zero, although our prejudice scores correlate at between 0.94 and 0.97 with similarly computed scores that do not do this recoding and so measure racial esteem as well as prejudice. The resulting variable ranges from zero to 100 . This is a widely used measure of racial prejudice that consistently predicts whites' policy attitudes and support for black candidates (Peffley, Hurwitz, and Sniderman 1997).

Our goal in specifying our models is to identify variables that are potentially correlated with both respondents' racial contexts and their prejudice levels. At the county level, we include the percentage foreign born, the percentage with a bachelor's degree, and the percentage unemployed, either in 2010 or when the respondent was approximately 16 years old. By conditioning on county-level education levels, we seek to address socioeconomic status, one alternate channel through which contexts can shape racial attitudes. The unemployment measure seeks to capture job scarcity and economic stress.

Researchers aiming to measure the effect of a variable from earlier in the life course - such as high school contexts - on outcomes measured more recently face a model specification dilemma. To include independent variables measuring posttreatment attributes risks bias, as an independent variable such as respondents' educational attainment at the time of the survey may have been influenced by their high school context. However, to exclude such independent variables may risk omitted variable bias if those variables' high school analogs are unavailable or measured with error. We avoid this dilemma in the analyses of the YPSPS below by using a panel that measured key variables while respondents were in high school. In these

8. For the majority of respondents who turned 16 in a year when no census was conducted, we used linear interpolation to estimate their countylevel demographics for the year in which they were 16. In practice, this means taking a weighted average of the two most proximate census years.

9. The Cronbach's alphas for the prejudice measure on waves $3,4,5$, 6,7 , and 8 are respectively: $0.91,0.91,0.90,0.92,0.91$, and 0.93 . 
analyses of the 2007-13 panel, we follow Acharya et al. (2018b): our primary models omit any potentially posttreatment variables while models reported in the appendix (available online) demonstrate that the results are substantively identical when including them. ${ }^{10}$

\section{RESULTS FOR THE 2007-13 PANEL STUDY}

The 2007-13 panel allows us to reexamine the relationship between whites' racial attitudes and both contemporary and past racial contexts. A respondent's level of prejudice during one wave of the survey is likely to be correlated with her prejudice in other waves, so we initially combine the waves and model prejudice using a multilevel model with intercepts that vary by respondent.

Model 1 of table 1 reports the results of a baseline model that includes contemporary contextual measures for respondents' counties at the time of the survey. Such models are commonly provided as evidence that diverse racial contexts produce prejudice. As it shows, there is a strong relationship between the share of respondents' current county that is black and their prejudice, with a coefficient of 8.7 ( $\mathrm{SE}=3.1, p=$ .003). In model 2, however, we instead include a measure of respondents' racial contexts in high school and find an even stronger relationship $(\beta=12.8, \mathrm{SE}=3.6, p=.0002)$. When we compare a respondent who went to high school in a county with no blacks to one whose high school county was $18 \%$ black - one standard deviation above the mean - the latter scores 2.3 points higher on the prejudice scale, ${ }^{11}$ which is $15 \%$ of the dependent variable's standard deviation. When we include both contextual measures simultaneously in model 3, high school era contexts lose their straightforward causal interpretation, as contemporary racial contexts are posttreatment. Nonetheless, the predictive power of high school contexts is undiminished $(\beta=13.0, \mathrm{SE}=4.3, p=.004)$, while the contemporary racial context proves substantively small and statistically insignificant $(\beta=1.6, \mathrm{SE}=4.1, p=.70)$. Adolescent racial contexts are more predictive of prejudice than contemporary contexts, with the difference between the two coefficients in column 3 being 11.4 ( $\mathrm{SE}=5.9, p=.05)$. As table 5 shows, the results are substantively indistinguishable when conditioning on the richer set of individual-level variables detailed in note 10 .

10. For those models that do include individual-level covariates beyond age and gender, we follow recent work (Oliver and Mendelberg 2000; Oliver and Wong 2003) by including standard indicators of party identification (17), education (in years), income (in dollars), age, gender, marital status, and work status (with indicators for those no longer in the labor market because of retirement or disability).

11. The standard error associated with this estimate is 0.7 points.
Table 1. Multilevel Linear Models with Respondent Random Effects Predicting Prejudice (0-100)

\begin{tabular}{|c|c|c|c|}
\hline & Model 1 & Model 2 & Model 3 \\
\hline \multicolumn{4}{|l|}{ Individual factors: } \\
\hline Intercept & $\begin{array}{l}10.46^{*} \\
(2.35)\end{array}$ & $\begin{array}{c}8.27^{\star} \\
(2.75)\end{array}$ & $\begin{array}{l}10.22^{\star} \\
(3.34)\end{array}$ \\
\hline Age, 2008 & $\begin{array}{c}.04 \\
(.02)\end{array}$ & $\begin{array}{c}.05 \\
(.03)\end{array}$ & $\begin{array}{c}.04 \\
(.03)\end{array}$ \\
\hline Female, 2008 & $\begin{array}{r}-2.74^{*} \\
(.65)\end{array}$ & $\begin{array}{r}-3.12^{*} \\
(.70)\end{array}$ & $\begin{array}{r}-3.21^{\star} \\
(.72)\end{array}$ \\
\hline \multicolumn{4}{|l|}{ Contextual factors: } \\
\hline$\%$ black & $\begin{array}{c}8.68^{\star} \\
(3.10)\end{array}$ & & $\begin{array}{c}1.55 \\
(4.07)\end{array}$ \\
\hline \multicolumn{4}{|l|}{ Contemporary county } \\
\hline$\%$ immigrant & $\begin{array}{c}.32 \\
(4.39)\end{array}$ & & $\begin{array}{r}-4.10 \\
(5.41)\end{array}$ \\
\hline \multicolumn{4}{|l|}{ Contemporary county } \\
\hline$\%$ with $\mathrm{BA}$ & $\begin{array}{c}-5.99 \\
(4.21)\end{array}$ & & $\begin{array}{r}-5.30 \\
(4.88)\end{array}$ \\
\hline \multicolumn{4}{|l|}{ Contemporary county } \\
\hline$\%$ unemployed & $\begin{array}{c}-15.71 \\
(15.93)\end{array}$ & & $\begin{array}{l}-2.82 \\
(18.44)\end{array}$ \\
\hline HS county \% black & & $\begin{array}{l}12.81^{*} \\
(3.60)\end{array}$ & $\begin{array}{l}12.96^{*} \\
(4.33)\end{array}$ \\
\hline HS county $\%$ immigrant & & $\begin{array}{c}4.05 \\
(4.43)\end{array}$ & $\begin{array}{c}8.03 \\
(5.00)\end{array}$ \\
\hline HS county $\%$ with BA & & $\begin{array}{r}-5.25 \\
(4.40)\end{array}$ & $\begin{array}{r}-2.78 \\
(4.76)\end{array}$ \\
\hline HS county $\%$ unemployed & & $\begin{array}{c}-19.76 \\
(18.47)\end{array}$ & $\begin{array}{c}-25.08 \\
(19.60)\end{array}$ \\
\hline Observations & 7,603 & 5,918 & 5,760 \\
\hline Individuals & 1,693 & 1,321 & 1,285 \\
\hline
\end{tabular}

Source. 2007-13 Gf K panel.

Note. HS $=$ high school.

${ }^{*} p<.05$.

Prior scholarship has repeatedly documented correlations between white respondents' contemporary racial contexts and various race-related attitudes and interpreted those correlations as evidence of contextual influence. However, these results suggest a reinterpretation: contemporary racial contexts may appear influential because they are correlated with adolescent racial contexts. ${ }^{12}$ To investigate this possibility, we examined whether the impact of contemporary contexts appears primarily among the 533 respondents (38\%) who still live in the same county where they attended high school. Table 6 illustrates that

12. In this data set, the Pearson's correlation for the relationship between the percentage black in the respondent's contemporary county and in her high school-age county is 0.51 . 
the effects of contemporary racial contexts on prejudice are meaningful only for these respondents. The effect on this group is quite pronounced ( $\beta=17.9, \mathrm{SE}=6.0$ ), while for the majority who have moved it is essentially zero $(\beta=0.6$, $\mathrm{SE}=3.8)$. Put differently, the standard finding that contemporary racial contexts produce prejudice is driven entirely by the minority of respondents still living in the county where they attended high school. ${ }^{13}$

\section{MODERATORS AND ALTERNATIVE MODELS}

Given the paucity of measures of respondents' adolescent contexts, these data are limited in the extent to which they can identify the mechanisms at work. For that, we rely on analyses of the YPSPS below. Even so, we stand to learn more about the effect of adolescent racial contexts - and about the core effect's robustness - by examining whether those effects are stronger or weaker in certain counties or for certain respondents.

During the Civil Rights era, questions of race and racial integration were especially salient. As a consequence, it is possible that the effects of high school age racial contexts will vary with respondents' age. On the other hand, race-related divisions have continued to be a central aspect of American politics (Kinder and Dale-Riddle 2010; Tesler and Sears 2010). Moreover, older respondents are also further removed from their high school days, giving them a wider range of experiences and more time for attitude change. In table 7, we present models that separate respondents over and under 50. There is no significant difference, although the effect of adolescent contexts is somewhat stronger among younger respondents $(\beta=15.9$, $\mathrm{SE}=5.0)$ than older respondents $(10.5, \mathrm{SE}=5.7)$. While these results are consistent with an effect that fades slightly, the results strongly support our core hypothesis: adolescent racial contexts are a potent predictor of respondents' prejudice even decades later. This result proves robust to numerous other model specifications and coding decisions, such as recoding our prejudice measure to reduce the weight of outliers ${ }^{14}$ or including measures of adolescent or contemporary county-level partisanship (see table 8).

In the appendix, we discuss various other statistical models estimated on different subsets of respondents. These tests find no meaningful differences in the estimates when looking at

13. When we instead use respondents' high school contexts, we find that the relationship is again stronger among those who have not moved $(\beta=24.7, \mathrm{SE}=6.7)$ than for those who have moved $(\beta=8.2, \mathrm{SE}=4.3)$.

14. Our measure of prejudice is skewed, with a majority of respondents whose level is closer to zero and then a long tail of respondents with much higher scores. The mean level of prejudice is 8 on the $0-100$ scale, but the 90th percentile is 26 . Thus it is plausible that the core result is driven by a small number of high-prejudice respondents and the assumed linearity. Yet even when we respecify the dependent variable as $0-1$ indicators for respon- counties with different levels of unemployment or education (table 9). They also fail to detect meaningful differences when comparing respondents who do or do not report having had meaningful contact with blacks during high school (table 10).

Prior research has often analyzed different levels of aggregation to isolate the mechanisms likely to underpin contextual influences (Oliver and Wong 2003; Wong et al. 2012). Perhaps whites living in heavily white counties within a more diverse area are especially likely to show prejudice (Trounstine 2016). To consider that prospect, we calculated a new contextual measure that indicates the average percentage black in all the counties neighboring the respondent's county. As table 11 shows, this new measure does not change our main conclusions. ${ }^{15}$ Still, when we include this new measure in place of county-level racial contexts, we detect an effect of 16.6 (SE $=7.0, p=.002$ ), indicating that the relevant geographic area stretches beyond a single county. This finding suggests that general proximity, and not simply interpersonal exposure, produces prejudice. It is possible that broader units such as media markets or metropolitan areas are among the relevant geographies. However, the core result is similar when separating respondents who did or did not grow up in the South, meaning that it does not appear to be a product of Southern exceptionalism (see table 12) or regional effects.

\section{STUDY 2: THE 1965-97 PANEL SURVEY}

Many surveys of political attitudes do not release geographic information at a level of aggregation that enables contextual analyses. Even the ANES and other surveys that do make geographic information available overwhelmingly provide data only on respondents' contexts when surveyed. Perhaps uniquely, the YPSPS provides data on respondents' contexts at multiple times over decades. The YPSPS first interviewed American high school seniors in 1965 and then reinterviewed them in 1973, 1982, and 1997. By the 1997 wave, the respondents were approximately 50 years old. It thus provides a critical test of the claim that people's environments during adolescence are especially influential. Its surveys of the seniors' classmates and parents also enable researchers to measure various aspects of respondents' contexts, both social and demographic. In this section, we describe the YPSPS and our measures of respondents' contexts.

Using the 871 white panelists who participated in the 1997 wave, we first obtained restricted ZIP code information for

dents whose prejudice level puts them in the top $25 \%$ or top $50 \%$, the results are substantively quite similar.

15. This new measure correlates with the primary measure of adolescent racial context at 0.73 , so unsurprisingly, models that include both measures simultaneously indicate that both have positive but statistically insignificant effects. 
each respondent's home address as of 1982 and 1997, and for their high school as of $1965 .{ }^{16}$ We then used a combination of ZIP code maps and a 1982 ZIP code directory to identify the US counties corresponding to each respondent's residence during those waves. From there, we linked each respondent to US census data about her county's percentage black, percentage with a bachelor's degree, unemployment rate, and percentage immigrant at the time of the survey. ${ }^{17}$ This procedure successfully links every respondent to the county-level demographics corresponding to her high school (see also Nall 2015). It links all but 13 respondents to their 1982 county and all but 37 respondents to their 1997 county.

The racial demographics of respondents' counties are one measure of their social and demographic contexts, but there are others - and one key advantage of the YPSPS is that it provides various contextual measures. Accordingly, we also merged in data from three other surveys conducted as part of the YPSPS. The first is a brief survey of school administrators at all 97 high schools (91 of which had white students), which includes a question about the percentage of black students attending. Given the extent of school segregation, the mean percentage black in the white respondents' high schools is only $4.1 \%$, as compared to a mean county percentage black of $8.8 \%$. Those two measures correlate at a modest 0.15 , indicating that white students' high school contexts were not only very homogeneous but also not closely related to the broader, county-level context. A sizable number of the white respondents live in counties with many black neighbors while having few or no black classmates. Tables 13 and 14 provide individual, high school, and county-level descriptive statistics.

The measure of racial prejudice available from the YPSPS has a long track record of measuring intergroup attitudes (e.g., Hajnal 2001; Kinder and Kam 2009). Using two standard 0100 feeling thermometers, respondents separately rated how they felt toward whites and blacks. ${ }^{18}$ Whites' evaluations of blacks were then subtracted from their evaluations of whites to create a measure of in-group preference. ${ }^{19}$

To better understand respondents' familial and social contexts, we created measures of their parents' racial attitudes. Of the 871 white high school seniors in our data set, 580 mothers were interviewed and assessed whites and blacks using the

16. Note that such information was not available for the 1973 wave.

17. Respondents were linked to 1970 county demographics based on their 1965 high school's county, 1980 demographics based on their 1982 county, and 2000 demographics based on their 1997 county.

18. These feeling thermometers have been included on the American National Election Study (ANES) since 1964, which helps explain their prominence in measuring antiblack prejudice.

19. This measure correlates at 0.98 with a similarly constructed but asymmetric measure that recodes responses that rank blacks more highly than whites to zero. same feeling thermometers. For fathers, the figure was an overlapping 491. We then calculated the average parental selfreport (for panelists with two surveyed parents) or else took the available self-report where just one parent was surveyed. In total, this provides parental measures for all but 44 of the 871 high school seniors. The resulting measure of parents' racial prejudice is correlated at 0.27 with the children's 1965 racial attitudes.

The parents display substantial prejudice, with $68 \%$ of the 827 students for whom data is available having parents who rated whites more highly than blacks on average. In fact, the mean difference in parents' ratings of whites and blacks is a striking 20.1. The children's 1965 racial attitudes show substantial prejudice, too, but at a slightly lower level, with an average difference of 16.9 points; $57 \%$ of high school seniors rated whites more highly than blacks in $1965 .{ }^{20}$

We also drew on another part of the YPSPS to measure the students' social context by analyzing their high school peers' racial attitudes. Following Jennings et al. (2009), we used a question about the three things about the United States that made respondents least proud and then calculated the mean share of respondents in each school choosing "prejudice and discrimination against minority groups" to measure the racial attitudes of respondents' classmates. For 77 of the 91 schools and 704 of the 871 white respondents, we are thus able to use this survey of more than 20,000 high school students to calculate school-specific average racial attitudes. The correlation between these school-specific scores and white respondents' 1965 racial attitudes is a strong -0.37 : as more of white high school seniors' classmates report not being proud of discrimination, the respondents themselves are less likely to give whites ratings that are higher than blacks'. ${ }^{21}$

\section{YPSPS RESULTS}

In our initial analyses, we seek to mirror our analyses of the 2007-13 panel closely. Here, too, our dependent variable is prejudice. Our models include several potential confounders, including 1965 partisanship, gender, age in 1965, indicators for those who attended college or graduated from college, and the respondent's father's years of education. These variables were measured in 1965 and so allow us to avoid the dilemma of potentially posttreatment independent variables. At the county level, we condition on the population share that

20. By 1982 , the parent-child correlation attenuated to 0.09 , as average levels of prejudice dropped among the white student cohort by 3.8 points to 13.1 . In 1982 , exactly $50 \%$ of the student cohort rated whites more highly than blacks; it was almost identical (at 51\%) in 1997.

21. There is also a Pearson's correlation of -0.22 between parents' prejudice and high school classmates being ashamed of discrimination. Table 13 presents a table of correlations between the various contextual measures. 
is black, has a BA, or is unemployed using the 1970 census to measure these respondents' county-level contexts while in high school. We also couple data from the 1980 census with the respondents' location in 1982 and from the 2000 census with data from their location in 1997 to measure contemporary contexts.

In table 2, we replicate the results from the 2007-13 panel by combining the 1982 and 1997 waves of the YPSPS using a

Table 2. Results of Models of Prejudice Fit to the YPSPS

\begin{tabular}{|c|c|c|c|c|c|}
\hline & $\begin{array}{c}\text { Later Prejudice } \\
\text { (1) }\end{array}$ & $\begin{array}{c}\text { Prejudice } 82 \\
\text { (2) }\end{array}$ & $\begin{array}{c}\text { Prejudice } 97 \\
\text { (3) }\end{array}$ & $\begin{array}{c}\text { Prejudice } 82 \\
(4)\end{array}$ & $\begin{array}{c}\text { Prejudice } 97 \\
\text { (5) }\end{array}$ \\
\hline Intercept & $\begin{array}{c}36.27 \\
(19.15)\end{array}$ & $\begin{array}{c}43.23 \\
(23.47)\end{array}$ & $\begin{array}{l}25.98 \\
(29.45)\end{array}$ & $\begin{array}{r}47.25^{\star} \\
(23.87)\end{array}$ & $\begin{array}{c}25.94 \\
(30.24)\end{array}$ \\
\hline HS county $\%$ black & $\begin{array}{l}12.86^{\star} \\
(5.27)\end{array}$ & $\begin{array}{l}17.04^{\star} \\
(5.91)\end{array}$ & $\begin{array}{l}11.98 \\
(7.09)\end{array}$ & $\begin{array}{l}17.19^{*} \\
(6.85)\end{array}$ & $\begin{array}{l}10.10 \\
(8.12)\end{array}$ \\
\hline HS county $\%$ with BA & $\begin{array}{r}-12.59 \\
(8.92)\end{array}$ & $\begin{array}{r}-17.83 \\
(10.53)\end{array}$ & $\begin{array}{r}-17.24 \\
(12.58)\end{array}$ & $\begin{array}{r}-16.81 \\
(11.88)\end{array}$ & $\begin{array}{r}-11.08 \\
(13.48)\end{array}$ \\
\hline HS county $\%$ unemployed & $\begin{array}{c}-21.34 \\
(33.96)\end{array}$ & $\begin{array}{r}-78.10 \\
(40.02)\end{array}$ & $\begin{array}{c}14.82 \\
(48.39)\end{array}$ & $\begin{array}{r}-57.91 \\
(46.12)\end{array}$ & $\begin{array}{c}17.52 \\
(50.96)\end{array}$ \\
\hline Contemporary county $\%$ black & $\begin{array}{c}5.05 \\
(5.71)\end{array}$ & & & & \\
\hline Contemporary county $\%$ with BA & $\begin{array}{c}-5.57 \\
(6.32)\end{array}$ & & & & \\
\hline Contemporary county $\%$ unemployed & $\begin{array}{r}-16.17 \\
(27.10)\end{array}$ & & & & \\
\hline Attended college (1982) & $\begin{array}{l}-.60 \\
(1.51)\end{array}$ & $\begin{array}{c}.03 \\
(1.91)\end{array}$ & $\begin{array}{c}-1.58 \\
(2.28)\end{array}$ & $\begin{array}{l}-.13 \\
(1.94)\end{array}$ & $\begin{array}{c}-1.40 \\
(2.34)\end{array}$ \\
\hline Graduated from college (1982) & $\begin{array}{r}-5.52^{\star} \\
(1.36)\end{array}$ & $\begin{array}{r}-6.80^{\star} \\
(1.73)\end{array}$ & $\begin{array}{c}-3.81 \\
(2.06)\end{array}$ & $\begin{array}{r}-6.68^{*} \\
(1.75)\end{array}$ & $\begin{array}{r}-4.35^{\star} \\
(2.10)\end{array}$ \\
\hline HS party ID & $\begin{array}{r}-.02 \\
(.29)\end{array}$ & $\begin{array}{r}-.21 \\
(.37)\end{array}$ & $\begin{array}{c}.27 \\
(.44)\end{array}$ & $\begin{array}{r}-.18 \\
(.37)\end{array}$ & $\begin{array}{l}.12 \\
(.45)\end{array}$ \\
\hline Male, 1965 & $\begin{array}{c}.48 \\
(1.09)\end{array}$ & $\begin{array}{c}.92 \\
(1.39)\end{array}$ & $\begin{array}{c}.24 \\
(1.65)\end{array}$ & $\begin{array}{c}1.03 \\
(1.41)\end{array}$ & $\begin{array}{l}-.12 \\
(1.69)\end{array}$ \\
\hline Age, 1965 & $\begin{array}{l}-.84 \\
(1.02)\end{array}$ & $\begin{array}{l}-.99 \\
(1.27)\end{array}$ & $\begin{array}{l}-.64 \\
(1.59)\end{array}$ & $\begin{array}{c}-1.08 \\
(1.28)\end{array}$ & $\begin{array}{l}-.69 \\
(1.63)\end{array}$ \\
\hline Fathers' education, 1965 & $\begin{array}{c}-.11 \\
(.17)\end{array}$ & $\begin{array}{c}-.16 \\
(.21)\end{array}$ & $\begin{array}{c}-.02 \\
(.26)\end{array}$ & $\begin{array}{c}-.19 \\
(.22)\end{array}$ & $\begin{array}{c}-.03 \\
(.26)\end{array}$ \\
\hline Catholic, 1965 & $\begin{array}{c}-2.39 \\
(1.36)\end{array}$ & $\begin{array}{c}-3.12 \\
(1.71)\end{array}$ & $\begin{array}{c}-1.67 \\
(2.05)\end{array}$ & $\begin{array}{c}-2.78 \\
(1.76)\end{array}$ & $\begin{array}{c}-1.74 \\
(2.10)\end{array}$ \\
\hline Jewish, 1965 & $\begin{array}{c}-2.03 \\
(2.71)\end{array}$ & $\begin{array}{c}-1.74 \\
(3.39)\end{array}$ & $\begin{array}{r}-3.07 \\
(4.04)\end{array}$ & $\begin{array}{c}-1.46 \\
(3.47)\end{array}$ & $\begin{array}{c}-2.66 \\
(4.20)\end{array}$ \\
\hline County \% black in 1982 & & & & $\begin{array}{c}1.07 \\
(7.31)\end{array}$ & \\
\hline County \% with BA in 1982 & & & & $\begin{array}{c}-2.61 \\
(8.81)\end{array}$ & \\
\hline County \% unemployed in 1982 & & & & $\begin{array}{r}-38.93 \\
(32.86)\end{array}$ & \\
\hline County \% black in 1997 & & & & & $\begin{array}{c}5.93 \\
(9.26)\end{array}$ \\
\hline County \% with BA in 1997 & & & & & $\begin{array}{c}-7.40 \\
(9.58)\end{array}$ \\
\hline County \% unemployed in 1997 & & & & & $\begin{array}{c}36.57 \\
(50.93)\end{array}$ \\
\hline Observations & 1,536 & 791 & 787 & 779 & 757 \\
\hline
\end{tabular}

Note. The first model combines the 1982 and 1997 waves. YPSPS = Youth-Parent Socialization Panel Survey. HS = high school. ${ }^{*} p<.05$. 
multilevel model similar to that above but with additional individual-level covariates. This model has 1,536 observations from 779 respondents, with respondent random effects. As the first column demonstrates, respondents' high school racial contexts are a substantively and statistically significant predictor of prejudice in later years $(\beta=12.9, \mathrm{SE}=5.3$, $p=.02)$. When comparing otherwise similar white respondents who went to high school in counties that were $1 \%$ or $14 \%$ black - a shift from the first to the third quartilewe should expect prejudice to rise by 1.7 points ( $\mathrm{SE}=0.7$ ), which is $8 \%$ of this measure's standard deviation. By contrast, contemporary racial contexts prove a weaker and insignificant predictor $(\beta=5.05, \mathrm{SE}=5.7) .{ }^{22}$ High school contexts can influence prejudice, even decades later.

Prejudice is not fixed after adolescence, so we next consider high school racial contexts' effects separately in 1982 and 1997. The 1982 wave was administered 17 years after the 1965 wave, when the respondents were in their mid-thirties. As the second column of table 2 shows, high school racial contexts are a significant and sizable predictor of prejudice ( $\beta=17.0, \mathrm{SE}=5.9)$, and they remain so when accounting for contemporary racial contexts, as column 4 shows. A shift from the first-quartile county to the third-quartile county corresponds with an average increase in prejudice of 2.2 points. By comparison, the difference between these white high school students and their parents is 3.3 points. Notice in columns 3 and 5 that the effect of high school contexts remains a positive predictor of 1997 prejudice, one that is statistically indistinguishable from the effect on 1982 prejudice. However, the coefficients are no longer distinguishable from zero either $(\beta=12.0, \mathrm{SE}=7.1 ; p=.09 ; \beta=10.1, \mathrm{SE}=8.1, p=.21)$. While this pattern is consistent with some attenuation in the effects of high school contexts over time, we lack the precision needed to make firm conclusions about over-time changes. One added advantage of emphasizing adolescent racial contexts is that the threat of residential self-selection is somewhat tempered by the fact that adolescents live in places chosen by others. ${ }^{23}$

22. The difference between these two coefficients is not statistically significant (one-sided $p$-value $=.15$ ).

23. Nonetheless, the YPSPS can also shed light on the extent to which adolescent prejudice shapes respondents' racial contexts as adults and thus on the threat of selection bias in analyses of contemporary contexts (see also Nall and Mummolo 2017; Tam Cho, Gimpel, and Hui 2013). In table 19, we present the results of OLS models that predict respondents' 1997 racial contexts using various covariates, including their self-reported 1965 prejudice. At the county level, there is no strong evidence that more prejudiced high school seniors are living in areas with fewer blacks by 1997. One straightforward explanation for this is that residential selection might happen principally at smaller levels of aggregation (see also Oliver and Wong 2003).
Our analyses of the YPSPS uncovered a pattern consistent with the enduring influence of political socialization: high school racial contexts are stronger predictors of whites' prejudice than are contemporary racial contexts. But those respondents were high school seniors in 1965, a landmark year that saw the "Bloody Sunday" attack on marchers from Selma to Montgomery, the passage of the Voting Rights Act, the assassination of Malcolm X, and many other critical events in the Civil Rights movement. Those events could certainly have heightened whites' antiblack sentiments or else shaped local interactions and experiences. As a result, these analyses are especially powerful when viewed alongside those from the 2007-13 panel.

\section{ADDITIONAL MODELS AND MODERATORS}

As outlined above, there are a host of channels through which adolescent racial contexts might durably influence prejudice. Adolescent racial contexts might operate in very small social units, such as by shaping the racial attitudes whites encounter from their parents or peers. They might operate through interpersonal exposure to black students at school. Or they may operate at broader geographic levels, perhaps shaping the attitudinal or information environment in a county, media market, or metropolitan area. To consider those possibilities, we next fit models of prejudice in 1982 and 1997 that include not just the respondents' adolescent racial contexts but other measures of their social contexts during that formative period: their parents' prejudice levels, their classmates' concern about discrimination, and their high schools' percentage black.

High school contexts may shape prejudice through their influence on these other factors, so causal interpretation with these models is challenging. Still, they enable us to see the extent to which accounting for these other factors changes the estimated effect of county-level contexts. As table 3 demonstrates, we observe the same relationship between respondents' counties' percentage black during adolescence and later prejudice levels even with these added factors. For instance, columns 1 and 2 combine the 1982 and 1997 waves and report coefficients for county-level high school contexts of either $11.5(\mathrm{SE}=6.0, p=.06)$ or $13.4(\mathrm{SE}=6.7, p=$ $.05)$ accounting for parents' racial attitudes, classmates' racial attitudes, and high school demographics. ${ }^{24}$ Also, the percentage black in respondents' high schools is a negative predictor of prejudice $(\beta=-13.7, \mathrm{SE}=8.4)$-and while this effect is insignificant $(p=.10)$, it inveighs against the claim that interpersonal encounters in smaller social units are more likely

24. These various measures are correlated with each other, sometimes strongly so, making it unsurprising that the standard errors associated with the county-level contexts are larger. 
Table 3. Model of Prejudice Using the YPSPS

\begin{tabular}{|c|c|c|c|c|c|}
\hline & $\begin{array}{c}\text { Prejudice } \\
\text { (1) }\end{array}$ & $\begin{array}{c}\text { Prejudice } \\
\text { (2) }\end{array}$ & $\begin{array}{c}\text { Prejudice } 65 \\
\text { (3) }\end{array}$ & $\begin{array}{c}\text { Prejudice } 82 \\
\text { (4) }\end{array}$ & $\begin{array}{c}\text { Prejudice } 97 \\
\text { (5) }\end{array}$ \\
\hline Intercept & $\begin{array}{c}46.24^{*} \\
(17.76)\end{array}$ & $\begin{array}{r}45.35^{\star} \\
(17.82)\end{array}$ & $\begin{array}{c}51.72^{*} \\
(26.08)\end{array}$ & $\begin{array}{c}53.01^{*} \\
(24.13)\end{array}$ & $\begin{array}{c}38.86 \\
(25.67)\end{array}$ \\
\hline HS county $\%$ black & $\begin{array}{l}11.49 \\
(5.98)\end{array}$ & $\begin{array}{l}13.41^{*} \\
(6.65)\end{array}$ & $\begin{array}{l}39.76^{*} \\
(9.04)\end{array}$ & $\begin{array}{l}16.39^{*} \\
(8.33)\end{array}$ & $\begin{array}{c}5.13 \\
(8.40)\end{array}$ \\
\hline HS county $\%$ with BA & $\begin{array}{c}-3.13 \\
(8.72)\end{array}$ & $\begin{array}{c}-1.72 \\
(9.05)\end{array}$ & $\begin{array}{c}14.15 \\
(13.31)\end{array}$ & $\begin{array}{c}4.06 \\
(12.19)\end{array}$ & $\begin{array}{c}-12.89 \\
(12.32)\end{array}$ \\
\hline HS county \% unemployed & $\begin{array}{c}-50.91 \\
(28.82)\end{array}$ & $\begin{array}{r}-61.27^{\star} \\
(31.08)\end{array}$ & $\begin{array}{r}-55.71 \\
(43.68)\end{array}$ & $\begin{array}{r}-89.79^{\star} \\
(40.19)\end{array}$ & $\begin{array}{l}-9.86 \\
(40.98)\end{array}$ \\
\hline HS classmates' tolerance, 1965 & $\begin{array}{c}-5.41 \\
(4.07)\end{array}$ & $\begin{array}{c}-5.62 \\
(4.11)\end{array}$ & $\begin{array}{r}-40.60^{*} \\
(6.13)\end{array}$ & $\begin{array}{l}-9.68 \\
(5.65)\end{array}$ & $\begin{array}{c}-3.01 \\
(5.71)\end{array}$ \\
\hline Parents' prejudice, 1965 & $\begin{array}{c}3.71 \\
(2.35)\end{array}$ & $\begin{array}{c}3.73 \\
(2.36)\end{array}$ & $\begin{array}{l}15.38^{*} \\
(3.55)\end{array}$ & $\begin{array}{c}3.31 \\
(3.28)\end{array}$ & $\begin{array}{c}4.24 \\
(3.30)\end{array}$ \\
\hline$\%$ HS black & $\begin{array}{r}-13.70 \\
(8.44)\end{array}$ & $\begin{array}{r}-13.29 \\
(8.57)\end{array}$ & $\begin{array}{l}-9.00 \\
(11.73)\end{array}$ & $\begin{array}{l}-2.28 \\
(11.48)\end{array}$ & $\begin{array}{c}-22.51 \\
(12.36)\end{array}$ \\
\hline Attended college (1982) & $\begin{array}{c}-1.43 \\
(1.43)\end{array}$ & $\begin{array}{c}-1.39 \\
(1.44)\end{array}$ & $\begin{array}{l}-2.17 \\
(2.16)\end{array}$ & $\begin{array}{c}-1.08 \\
(2.00)\end{array}$ & $\begin{array}{c}-1.72 \\
(2.02)\end{array}$ \\
\hline Graduated from college (1982) & $\begin{array}{r}-5.19^{*} \\
(1.30)\end{array}$ & $\begin{array}{r}-5.11^{\star} \\
(1.30)\end{array}$ & $\begin{array}{l}-.24 \\
(1.96)\end{array}$ & $\begin{array}{r}-6.06^{*} \\
(1.82)\end{array}$ & $\begin{array}{r}-3.85^{\star} \\
(1.82)\end{array}$ \\
\hline Party ID, 1965 & $\begin{array}{r}-.34 \\
(.28)\end{array}$ & $\begin{array}{l}-.34 \\
(.29)\end{array}$ & $\begin{array}{c}.37 \\
(.43)\end{array}$ & $\begin{array}{l}-.59 \\
(.40)\end{array}$ & $\begin{array}{c}.02 \\
(.40)\end{array}$ \\
\hline Male, 1965 & $\begin{array}{l}-.42 \\
(1.04)\end{array}$ & $\begin{array}{l}-.46 \\
(1.04)\end{array}$ & $\begin{array}{c}1.54 \\
(1.57)\end{array}$ & $\begin{array}{l}-.02 \\
(1.45)\end{array}$ & $\begin{array}{l}-.76 \\
(1.45)\end{array}$ \\
\hline Age, 1965 & $\begin{array}{r}-1.16 \\
(.94)\end{array}$ & $\begin{array}{r}-1.14 \\
(.95)\end{array}$ & $\begin{array}{l}-.78 \\
(1.38)\end{array}$ & $\begin{array}{c}-1.34 \\
(1.28)\end{array}$ & $\begin{array}{l}-.93 \\
(1.37)\end{array}$ \\
\hline Father's education, 1965 & $\begin{array}{c}-.10 \\
(.17)\end{array}$ & $\begin{array}{c}-.08 \\
(.17)\end{array}$ & $\begin{array}{r}-.16 \\
(.25)\end{array}$ & $\begin{array}{c}-.15 \\
(.23)\end{array}$ & $\begin{array}{c}-.01 \\
(.23)\end{array}$ \\
\hline Catholic, 1965 & $\begin{array}{c}-2.04 \\
(1.35)\end{array}$ & $\begin{array}{c}-2.11 \\
(1.35)\end{array}$ & $\begin{array}{l}-.64 \\
(2.02)\end{array}$ & $\begin{array}{c}-2.05 \\
(1.87)\end{array}$ & $\begin{array}{c}-1.40 \\
(1.89)\end{array}$ \\
\hline Jewish, 1965 & $\begin{array}{l}-.80 \\
(3.07)\end{array}$ & $\begin{array}{l}-.56 \\
(3.09)\end{array}$ & $\begin{array}{c}-3.50 \\
(4.50)\end{array}$ & $\begin{array}{c}-2.30 \\
(4.21)\end{array}$ & $\begin{array}{l}-.33 \\
(4.27)\end{array}$ \\
\hline Contemporary county $\%$ black & & $\begin{array}{c}-3.75 \\
(5.62)\end{array}$ & & & \\
\hline Contemporary county $\%$ with BA & & $\begin{array}{c}-1.19 \\
(5.34)\end{array}$ & & & \\
\hline Contemporary county \% unemployed & & $\begin{array}{c}18.55 \\
(23.66)\end{array}$ & & & \\
\hline Observations & 1,196 & 1,196 & 628 & 616 & 613 \\
\hline No. of waves & 2 & 2 & 1 & 1 & 1 \\
\hline
\end{tabular}

Note. The first two columns report joint models of prejudice in 1982 and 1997, while the other columns report separate models by panel wave. YPSPS = Youth-Parent Socialization Panel Survey. HS = high school. ${ }^{*} p<.05$.

to produce prejudice. ${ }^{25}$ These results suggest that it is not simply that white people growing up in more heavily black

25. Given how coarse our measures of high school contexts are even in the YPSPS, and given the strong assumptions required, we leave to future work the challenge of estimating models of mediation such as those detailed by Acharya, Blackwell, and Sen (2018a). counties have more prejudiced parents or peers - the effect of racial demographics remains notable after accounting for those pathways.

In table 3's columns 3-5, we present separate results for three panel waves-1965, 1982, and 1997. While losing statistical precision, breaking out the results by year allows us to identify the potentially shifting roots of whites' prejudice. For 
instance, parents' racial attitudes have an initially powerful relationship with their children's racial attitudes that declines markedly, from 15.4 in 1965 to 3.3 in 1982. Parental influence appears to wane once the respondents are in their thirties. A shift from the first to the third quartile of parental prejudice is associated with an increase of 0.99 in prejudice, which is less than half of the change associated with shifting the adolescent racial context by the same magnitude. ${ }^{26}$ The influence of respondents' classmates' tolerance follows a similar pattern, as it is strong in $1965(\beta=-40.6, \mathrm{SE}=6.1)$ but declines by $1982(\beta=-9.7, \mathrm{SE}=5.7)$. Overall, these analyses indicate that adolescent contexts continue to be influential even accounting for some of the social channels through which they were hypothesized to operate. This pattern of results bolsters the possibility that the relevant spatial units are larger than families or high schools - and that the underlying mechanism is likely to be information or attitudinal environments acting beyond people's immediate social contexts. The impact of the broader community appears more durable than those of family or peer contexts.

In the appendix, we replicate several of the robustness checks performed on the 2007-13 panel, including examining the results for heterogeneity by mobility (table 16), counties' economic distress (table 17), or growing up in the South (table 18). The results reinforce those above, indicating that contemporary racial contexts are much more predictive of prejudice among respondents still living in the same counties where they went to high school $(\beta=31.4, \mathrm{SE}=9.9)$.

\section{DISCUSSION AND CONCLUSION}

Social scientists have become increasingly concerned that empirical results from quantitative, observational studies like this one are the product of specification searches and so are sensitive to modeling choices. One strong defense against this challenge is to test hypotheses by applying similar statistical models to two independent data sets. Here, we did precisely that. We tested the relationship between respondents' adolescent contexts and prejudice using two different panel surveys that differ in their timing, sampling frame, survey mode, and measures. Irrespective of whether we analyze a 2007-13 online, population-based panel of adults or a 1965-97 cohort study, the core finding holds: white Americans who were adolescents in counties with larger black populations are more racially prejudiced decades later. Moreover, this relationship is quite robust. It holds true accounting for other influential aspects of the respondents' adolescent contexts, such as their

26. We also considered the related possibility that parents' racial attitudes are more easily transmitted in areas with larger black communities but found no evidence for this hypothesis. parents' and classmates' racial attitudes. The effect is also substantively meaningful. As the YPSPS results make clear, 17 years after high school, respondents' racial contexts during high school are a more powerful predictor of their prejudice than their parents' racial attitudes. There is suggestive evidence that the magnitude of the effect declines as the respondents age, a finding in keeping with the notion that racial attitudes can be responsive to events and experiences in adulthood as well.

In the decades since Key's Southern Politics, there have been scores of studies of racial contexts, studies whose results are collectively inconclusive about the strength and preconditions of prejudiced responses by whites. The results here provide one explanation for the inconsistency of prior research: by focusing almost exclusively on contemporary contexts' impacts on adults, it has neglected the adolescent residential contexts that are especially influential. Since many whites do not remain in the communities where they grew up, estimates that consider only contemporary contexts reflect an unknown combination of prior and present-day contextual influences.

Prior research often interprets the correlations between whites' current contexts and their racial attitudes as evidence of racial threat. To the extent that whites become more hostile to blacks living nearby, it seems plausible that such hostility might reflect realistic group conflict, as whites and blacks compete for jobs, power, or other scarce resources. But these results undercut such interpretations: once we account for early-life socialization, contemporary racial contexts are not predictive of prejudice. Instead, they bolster claims that intergroup bias has nonmaterial origins, as it reflects people's early-life experiences and socialization in larger geographic units.

Even as it answers specific questions, this research raises others. It measures only high school and contemporary racial contexts and so ignores other contexts that might prove influential, from elementary school to college. Recent contextual research has made significant progress by considering various geographic contexts that might be influential (Dinesen and Sonderskov 2015; Moore and Reeves 2017). One important next step is to consider the effects of different contexts over time as well as across space. Researchers would do well to study the accumulation of contextual influence over the life course. Studying people who moved during adolescence and studying contextual influence on groups other than whites are valuable next steps as well. Research on racial contexts has focused heavily on the so-called threatened group — non-Hispanic whites - with far less attention to the social and political effects of whites' attitudes and proximity on neighboring blacks. Considering the effects of adolescent contexts for blacks and other communities of color seems a critical direction for future research. 
These findings also reinforce the importance of continuing to isolate the mechanisms through which racial contexts exert influence. Local racial demographics might influence adolescents' attitudes through multiple pathways, from their casual encounters with blacks to the attitudes of their parents, teachers, and peers to other community socialization agents such as churches and clubs. The extensive data available about the YPSPS respondents' contexts allows us to downplay a few channels of influence, such as the demographics of whites' high schools. They suggest instead that the operative units are larger, whether they are media markets, metropolitan areas, or information environments. But contextual effects are not static over time, nor are high school demographics. What is more, various perceptual and social mechanisms remain plausible in light of these results and so require further improvements in measurement.

Well into the twenty-first century, the depth and influence of antiblack prejudice remains striking. By showing the enduring influence of whites' adolescent racial contexts, these results provide insight into the persistence of prejudice generally. To a meaningful extent, racial attitudes are the product of particular experiences in particular places - and at particular moments in whites' pathways to adulthood.

\section{ACKNOWLEDGMENTS}

We gratefully acknowledge research assistance by Tiger Brown, Zoe Dobkin, Saleel Huprikar, Louis Lin, Thomas Munson, and Samantha Washington. We also thank Matthew Blackwell, Ryan Enos, Andrew Gelman, James Gimpel, Eric Gonzalez Juenke, Georgia Ray, Timothy Ryan, Melissa Sands, participants at the 2014 annual meeting of the American Political Science Association, the Class, Race, and Ethnicity Workshop at Michigan State University, the American Politics Workshop at the University of Massachusetts at Amherst, the 2015 Comparative Approaches to the Study of Immigration, Ethnicity, and Religion Workshop at the University of North Carolina, and the 2015 Harvard Meeting on Political Geography. We acknowledge assistance from the University of Michigan's Inter-university Consortium for Political and Social Research in obtaining restricted geographic information for the YPSPS.

\section{REFERENCES}

Acharya, Avidit, Matthew Blackwell, and Maya Sen. 2018a. "Analyzing Causal Mechanisms in Survey Experiments." Political Analysis 26 (4): 357-78.

Acharya, Avidit, Matthew Blackwell, and Maya Sen. 2018b. Deep Roots: How Slavery Still Shapes Southern Politics. Vol. 6. Princeton, NJ: Princeton University Press.

Bigler, Rebecca S., and Lynn S. Liben. 2007. "Developmental Intergroup Theory Explaining and Reducing Children's Social Stereotyping and Prejudice." Current Directions in Psychological Science 16 (3): 162-66.
Blinder, Scott B. 2007. "Dissonance Persists: Reproduction of Racial Attitudes among Post-Civil Rights Cohorts of White Americans." American Politics Research 35 (3): 299-335.

Dancygier, Rafaela. 2010. Immigration and Conflict in Europe. Princeton, NJ: Princeton University Press.

Dinesen, Peter Thisted, and Kim Mannemar Sonderskov. 2015. "Ethnic Diversity and Social Trust: Evidence from the Micro-Context." American Sociological Review 80 (3): 550-73.

DuRocher, Kristina. 2011. Raising Racists: The Socialization of White Children in the Jim Crow South. Lexington: University Press of Kentucky.

Enos, Ryan D. 2017. The Space between Us: Social Geography and Politics. New York: Cambridge University Press.

Gerard, Harold B. 1988. "School Desegregation: The Social Science Role." In Phyllis A. Katz and Dalmas A. Taylor, eds., Eliminating Racism: Profiles in Controversy. New York: Plenum, 225-36.

Glaser, James M. 1994. "Back to the Black Belt: Racial Environment and White Racial Attitudes in the South." Journal of Politics 56 (1): 21-41.

Glaser, James M., and Martin Gilens. 1997. "Interregional Migration and Political Resocialization: A Study of Racial Attitudes under Pressure.” Public Opinion Quarterly 61 (1): 72-86.

Glaser, James M., and Timothy J. Ryan. 2013. Changing Minds, If Not Hearts: Political Remedies for Racial Conflict. Philadelphia: University of Pennsylvania Press.

Goldman, Seth K., and Diana C. Mutz. 2014. The Obama Effect: How the 2008 Campaign Changed White Racial Attitudes. New York: Russell Sage Foundation.

Hajnal, Zoltan L. 2001. "White Residents, Black Incumbents, and a Declining Racial Divide." American Political Science Review 95 (3): 603-17.

Hersh, Eitan, and Clayton Nall. 2016. "The Primacy of Race in the Geography of Income-Based Voting: New Evidence from Public Voting Records." American Journal of Political Science 60 (2): 289-303.

Hopkins, Daniel J. 2010. "Politicized Places: Explaining Where and When Immigrants Provoke Local Opposition.” American Political Science Review 104 (1): 40-60.

Hopkins, Daniel J. 2012. "Flooded Communities: Explaining Local Reactions to the Post-Katrina Migrants.” Political Research Quarterly 65 (2): 443-59.

Jennings, M. Kent, Laura Stoker, and Jake Bowers. 2009. "Politics across Generations: Family Transmission Reexamined." Journal of Politics 71 (3): 782-99.

Key, V. O. 1949. Southern Politics in State and Nation. New York: Knopf.

Kinder, Donald R., and Allison Dale-Riddle. 2010. The End of Race? Obama, 2008, and Racial Politics in America. New Haven, CT: Yale University Press.

Kinder, Donald R., and Cindy D. Kam. 2009. Us against Them: Ethnocentric Foundations of American Opinion. Chicago: University of Chicago Press.

Miller, Steven D., and David O. Sears. 1986. "Stability and Change in Social Tolerance: A Test of the Persistence Hypothesis." American Journal of Political Science 30:214-36.

Moody, James. 2001. "Race, School Integration, and Friendship Segregation in America." American Journal of Sociology 107 (3): 679-716.

Moore, Ryan T., and Andrew Reeves. 2017. "Learning from Place in the Era of Geolocation.” In Benjamin Ginsberg, Kathy Wagner Hill, and Jennifer Bachner, eds., Analytics, Policy and Governance. New Haven, CT: Yale University Press.

Nall, Clayton. 2015. "The Political Consequences of Spatial Policies: How Interstate Highways Facilitated Geographic Polarization.” Journal of Politics 77 (2): 394-406.

Nall, Clayton, and Jonathan Mummolo. 2017. "Why Partisans Don't Sort: How Quality and Resource Constraints Prevent Political Segregation.” Journal of Politics 79 (1): 45-59. 
Newman, Benjamin J. 2012. "Acculturating Contexts and Anglo Opposition to Immigration in the United States." American Journal of Political Science 57:374-90.

Niemi, Richard G., and M. Kent Jennings. 1991. "Issues and Inheritance in the Formation of Party Identification." American Journal of Political Science 35:970-88.

Oliver, J. Eric. 2001. Democracy in Suburbia. Princeton, NJ: Princeton University Press.

Oliver, J. Eric, and Tali Mendelberg. 2000. "Reconsidering the Environmental Determinants of White Racial Attitudes." American Journal of Political Science 44 (3): 574-89.

Oliver, J. Eric, and Janelle Wong. 2003. "Intergroup Prejudice in Multiethnic Settings.” American Journal of Political Science 47 (4): 567-82.

Peffley, Mark, Jon Hurwitz, and Paul M. Sniderman. 1997. "Racial Stereotypes and Whites' Political Views of Blacks in the Context of Welfare and Crime." American Journal of Political Science 41 (1): 3060.

Pettigrew, Thomas F., and Linda R. Tropp. 2011. When Groups Meet: The Dynamics of Intergroup Contact. New York: Psychology Press.

Putnam, Robert D. 2007. "E Pluribus Unum: Diversity and Community in the 21st Century." Scandinavian Political Studies 30 (2): 137-74

Ritterhouse, Jennifer Lynn. 2006. Growing Up Jim Crow: How Black and White Southern Children Learned Race. Chapel Hill: University of North Carolina Press.

Rothbart, Myron, and Oliver P. John. 1985. "Social Categorization and Behavioral Episodes: A Cognitive Analysis of the Effects of Intergroup Contact." Journal of Social Issues 41 (3): 81-104.

Schuman, Howard, Charlotte Steeh, Lawrence Bobo, and Maria Krysan. 1997. Racial Attitudes in America: Trends and Interpretations. Cambridge, MA: Harvard University Press.
Sears, David O., and Carolyn L. Funk. 1999. "Evidence of the Long-Term Persistence of Adults Political Predispositions." Journal of Politics 61 (1): $1-28$.

Sears, David O., and Sheri Levy. 2003. "Childhood and Adult Political Development." In David O. Sears, Leonie Huddy, and Robert Jervis, eds., Oxford Handbook of Political Psychology. New York: Oxford University Press.

Sears, David O., and Nicholas A. Valentino. 1997. "Politics Matters: Political Events as Catalysts for Preadult Socialization." American Political Science Review 91 (1): 45-65.

Stolle, Dietlind, and Allison Harell. 2013. "Social Capital and Ethno-Racial Diversity: Learning to Trust in an Immigrant Society." Political Studies 61:42-66.

Tam Cho, Wendy K., James G. Gimpel, and Iris S. Hui. 2013. "Voter Migration and the Geographic Sorting of the American Electorate." Annals of the Association of American Geographers 103 (4): 856-70.

Tesler, Michael, and David O. Sears. 2010. Obama's Race: The 2008 Election and the Dream of a Post-racial America. Chicago: University of Chicago Press.

Trounstine, Jessica. 2016. "Segregation and Inequality in Public Goods." American Journal of Political Science 60 (3): 709-25.

Welch, Susan, Lee Sigelman, Timothy Bledsoe, and Michael Combs. 2001. Race and Place: Race Relations in an American City. New York: Cambridge University Press.

Wong, Cara, Jake Bowers, Tarah Williams, and Katherine Drake Simmons. 2012. "Bringing the Person Back In: Boundaries, Perceptions, and the Measurement of Racial Context.” Journal of Politics 74 (4): 1153-70.

Wright, Gerald C. 1977. "Contextual Models of Electoral Behavior: The Southern Wallace Vote.” American Political Science Review 71 (2): 497508. 
Copyright of Journal of Politics is the property of The Southern Political Science Association and its content may not be copied or emailed to multiple sites or posted to a listserv without the copyright holder's express written permission. However, users may print, download, or email articles for individual use. 